\title{
Ebstein's Anomaly: Anesthetic Management at shahid Gangalal National Heart Centre
}

\author{
Upreti $\mathrm{MR}^{*}$, Pokhrel JN* \\ *Shahid Gangalal National Heart Centre \\ Corresponding: Dr. Murari Raj Upreti \\ Shahid Gangalal National Heart Centre, Bansbari, Kathmandu, Nepal Tel: 00977-1-4371322, 00977-1-4371347. \\ Fax 00977-1-4371123
}

\begin{abstract}
During the last eight years, $34 \%$ of the cases have been congenital; out of which only $0.7 \%$ have been Ebstein's Anomaly. In the literature they have mentioned that the male and female ratio is 1:1, but there are more female than male in our series, 15:3.
\end{abstract}

Keywords : congenital, Ebstein's Anomaly, right ventricle, tricuspid valve

\section{INTRODUCTION}

Ebstein anomaly is a rare congenital heart disease having an incidence of $0.3-0.6 \%$ of all congenital heart disease. Both sexes are equally affected. Lithium exposure during pregnancy can cause Ebstein's anomaly.

During the period of eight years we did 6035 total cardiac operation in our center which includes congenital, valve surgery and vascular surgery. In the first year it was over 200 cases; however this year, more that 1200 cases have been done. All cases have undergone general anesthesia.

Out of the 6035 total cases $34 \%, 0.73 \%$ (15 cases) were Ebstein's anomaly, among them three were male and twelve female. The age distribution ranged from 6 years to 30 years. There have been no Ebstein's cases under the age of 4 years in our series.

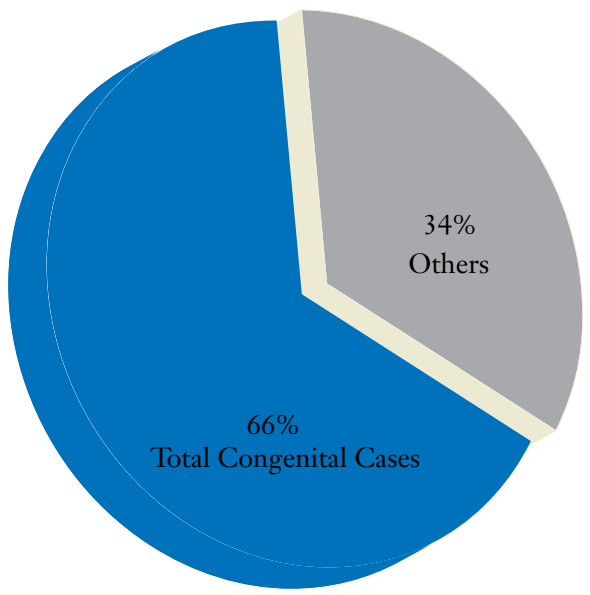

Figure 1: Total congenital cases in SGNHC

\section{HISTORY}

Dr. Wihelm Ebstein, physician in Poland described the clinical finding of an adolescent man who died of cyanotic congenital heart disease in 1866 . He correlated his postmortem finding with the notes given by his colleague. In 1949, first Ebstein case was diagnosed in a living person. The first surgery was done by Wright and his colleague in 1954 and it was direct closure of foramen ovale.

Hunter and his friend repairedthe tricuspid valve in 1958. In 1963, Burnard and Schrise replaced the tricuspid valve. This was the mechanical prosthetic valve.

Im Mayo clinic, 1972, they did the plication of the arterialized portion of the right ventricle, tricuspid anuloplasty and reduction atrioplasty of the right atrium which was better than valve replacement in many aspects.

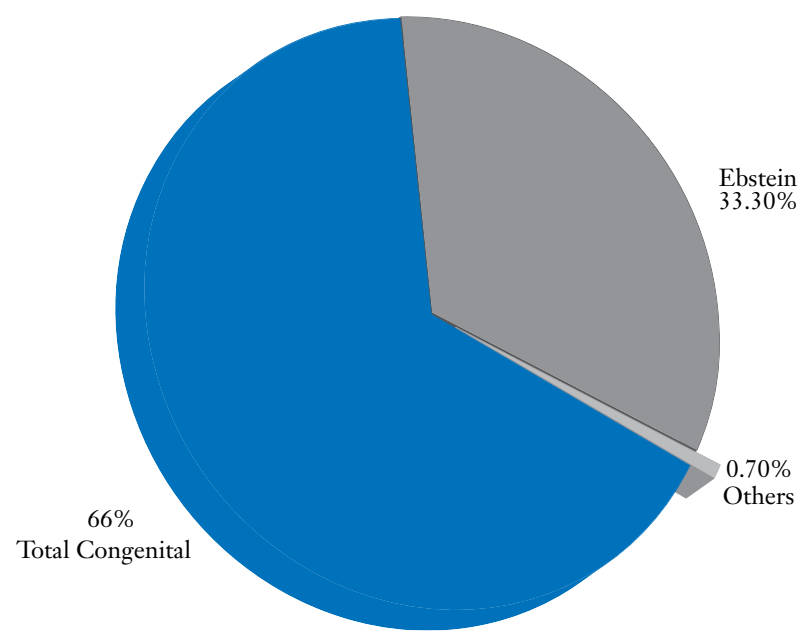

Figure 2: Percentage of Ebstein

\begin{abstract}
Anatomy
Ebstein anomaly is the disease of right ventricle and tricuspid valve. Normally tricuspid valve is formed by the process of delamination of the inner layer of the myocardium of the right ventricle. There is a defect in the delamination of the right ventricle, so there is an spical displacement of the tricuspid valve annulus: Septal and posterior leaflet are
\end{abstract}


displaced downwards and the anterior leaflet of tricuspid valve is elongated.

Papillary muscle and chordae are also abnormal. Tricuspid valve is displaced downwards so there is atrialized portion of the right ventricle and the functional right ventricle is small. Tricuspid valve may be stenotic or imperforated. There may be associated anomalies like atrial sptal defect, ventricular septal defect, pulmonary stenosis, transposition of great arteries or WPW (Wolf Parkinson white Syndrome).

\section{Pathophysiology}

There is severe tricuspid regurgitation due to tricuspid valve anomaly which leads to dilated right atrium with right to left shunting of the blood at arterial level which reduces the pulmonary flow. The pulmonary flow may be reduced by pulmonary obstruction due to abnormal tricuspid valve tissue, elevated pulmonary vascular resistance and tricuspid regurgitation. There is a severe right ventricular volume overload due to tricuspid regurgitation. Right ventricle is enlarged and it displaces the septum towards the left ventricle. The function of the left ventricle is compromised which may lead to pathological fibrosis of left ventricle. The atrium is enlarged and it can have abnormal conducting system like WPW (Wolf Parkinson White Syndrome) or AVNRT (AtrioVentricular Nodal Reentry Tract).

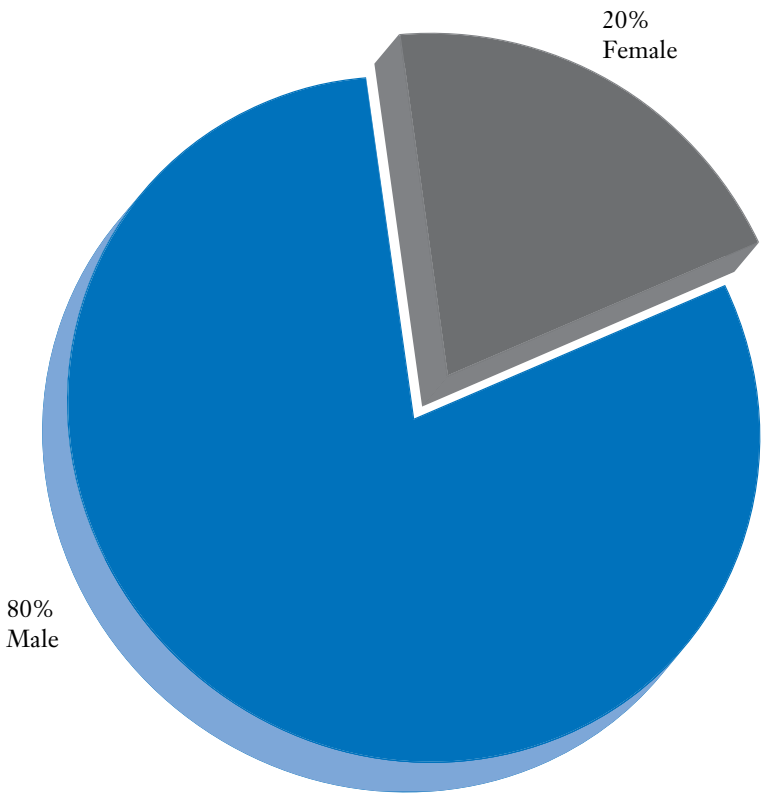

Figure 3: Male and Female ratio in Ebstein

\section{Clinical presentation}

Cyanosis is the most common presentation in infancy. Mild cyanosis can be managed by oxygen when pulmonary vascular resistance improves after time, but severe tricuspid regurgitation may go into failure and circulatory collapse, leading to death within a few hours. Because of conduction defect they can cause supraventricular tachycardia which may lead to the presenting symptoms. Mortality rate is very high in infants, almost $20 \%$, if they present very early in life. In they survive beyond the neo natal period the common presenting age is $4-5$ years and presenting symptoms will be dyspnes on exertion and congestive heart failure. Neurological complication such as cerebrovascular accident and brain abscess may occur. They can develop infective endocarditis, Left ventricular dysfunction. Left ventricular dysfunction is due to dilated right ventricle and bowing of the interventricular septum toward the left causing filling defect.

\section{Indication for surgery}

Severe cyanosis with polycythmia, progressive heart failure, left to right shunt more than 2:1, paradoxical immobilization and severe arrhythmias are the indication for surgery.

\section{Physical examination}

In neonates and older children, cyanosis is usually present. Regurgitant systolic murmur caused by tricuspid regurgination found to the left or the sternum. Right ventricular delayed emptying will produce wide splitting of second heart sound as well as gallop rhythm.
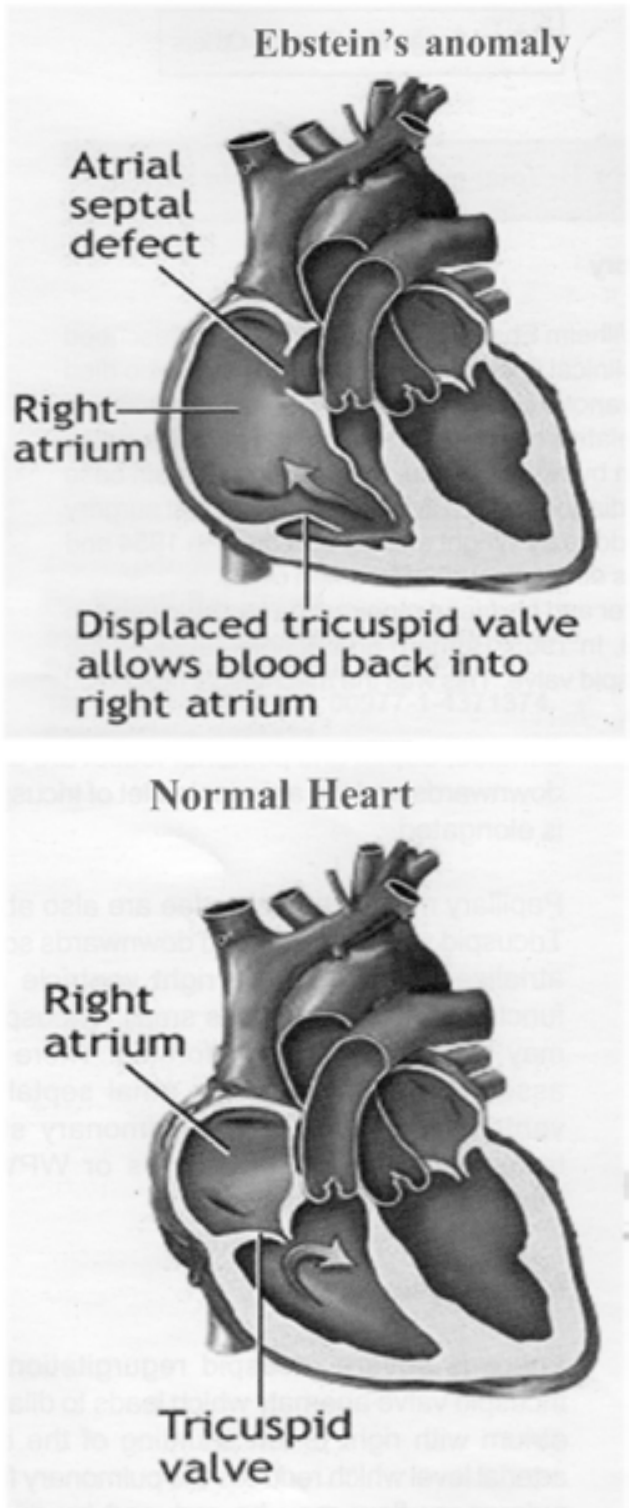

Figure 4: Normal and Heart with Ebstein's Anomaly 


\section{Chest radiograph}

Extreme Cardiomegaly can be found due to massively enlarged right atrium in the chest radiograph. Usually, pulmonary vascular markings is reduced due to low pulmonary flow or raised pulmonary vascular resistance.

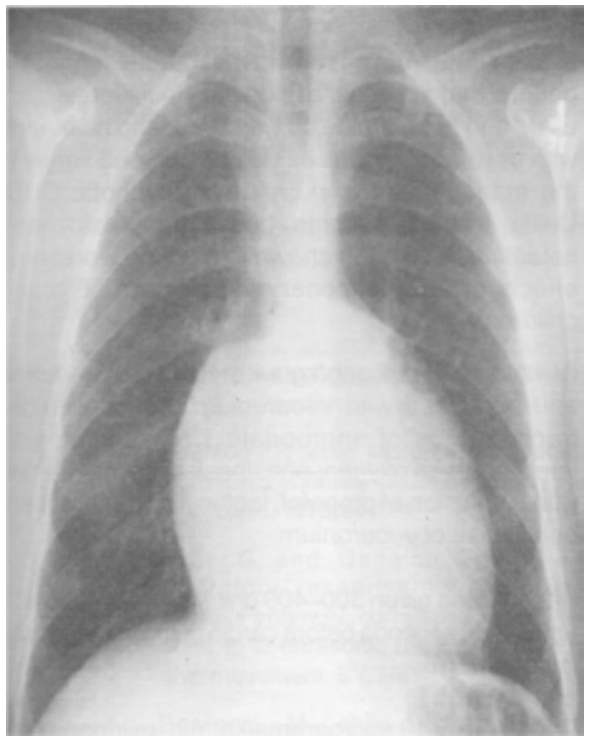

Figure 5: X-ray chest of Ebstein's anomaly

\section{Electrocardiography}

About $50 \%$ of individuals with Ebstein's anomaly have evidence of Wolff-Parkinson-White syndrome, secondary to the atrialized right ventricular tissue. Other abnormalities that can be seen on the ECG include (1) signs of right arterial enlargement or tall and broad 'Himalayan' $\mathrm{P}$ waves, (2) first degree atrioventricular block manifesting as a prolonged PR-interval, (3) low amplitude QRS complexes in the right precordial leads, (4) atypical right bundle branch block, (5) $\mathrm{T}$ wave inversion in V1-V4 and Q waves in V1-V4 and II, III and $\mathrm{aVF}$.

\section{Echocardiography}

Echocardiography is the key diagnostic tool for the diagnosis of the Ebstein's anomaly. It can provide anatomical as well as physiological information about the heart.

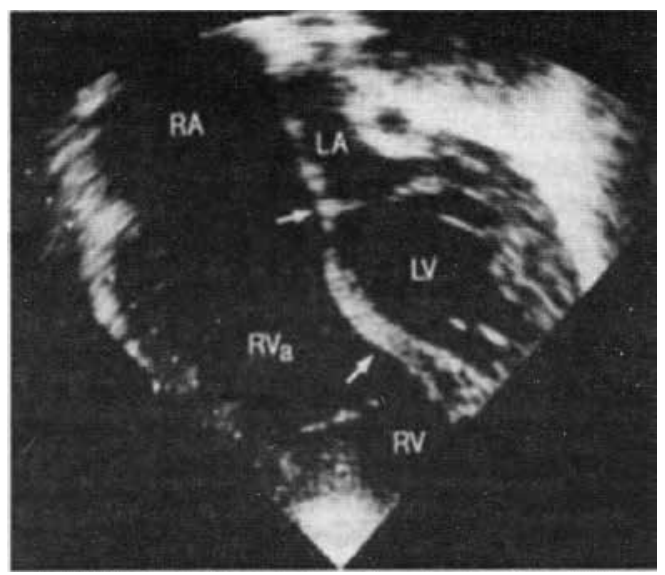

Figure 6: Echovardiograph of Ebstein's anomaly
Displaced septal and posterior leaflet as well as the redundant anterior leaflet is easily seen. Tricuspid regurgitation or stenosis is demonstrated by color Doppler. Right Atrium is enlarged and right to left shunt at atrial level can be demonstrated. Pulmonary blood flow can be estimated by color Doppler.

\section{Cardiac Catheterization}

Cardiac catheterization is usually not done because of the risk of perforation, bit if needed it is done where the right to left shunt can be measured but cardiac catheterization is more importantly used for the ablation of abnormal conducting system.

\section{Pre-operative management}

Sedation, paralysis and intubation are needed if the patient is very sick. Hyper ventilation is needed to reduce the pulmonary vascular resistance but care must be taken that the endo-tracheal tube should be watched out for.

In the neonate, in order to open the ductus arterious, to increase the pulmonary blood flow, prostaglandin E1 infusion is necessary.

Patients may have pulmonary hypertension and metabolic acidosis, thus measures should be taken to reduce pulmonary hypertension by oxygenation, vasodilator like GTN or nitric oxide, alpha-adrenergic agonist. Correction of metabolic acidosis is important because it can improve the myocardial function and reduce the pulmonary vascular resistance. Patient may need appropriate inotropic support as they have a low cardiac output, however epinephrine should be avoided since it can raise the pulmonary vascular resistance in high dose. Fluid administration should be minimized in view of the fact that it can increase the tricuspid regurgitation hence the central venous pressure should be less than $10 \mathrm{~mm} \mathrm{Hg}$.

\section{Precautions}

There is a communication between left and right side of the heart. There is absolute necessity of an IV line that is free of air bubble. While giving drug precaution should be taken against air being pushed in.

Endo tracheal tube should be kept in a right position because one lung vantilation can produce barotrauma and hypoxia.

During Central Venous Catheter Placement, extra precaution must be taken because the patient can develop arrhythmia and perforation of right atrium.

\section{Monitoring system during anesthesia}

The following monitoring system is required for the anesthetic management-

- $\mathrm{SPO} 2$

- ECG

- ETCO2

- Temperature

- Arterial BP measurement

- CVP

- Urine Output

- ACT

- $\mathrm{ABG}$ and electrolytes

\section{Anesthetic Management}

It is important to understand the anatomy and Pathophysiology of Ebstein's Anomaly and associated intra and 
extra cardiac defect before anesthetic management. It is also essential to identify the drugs and their pharmacology, which maintains the pulmonary and systemic pressure. It should be kept in mind that patients are prone to develop arrhythmia, especially arterial type.

Deformed tricuspid valve and increased pulmonary vascular resistance causes right to left shunt at arterial and ventricular level and there is a high chance of right ventricular failure while patients come up from cardio pulmonary bypass or immediate post operative period.

\section{Induction and maintenance of anesthesia}

Recent data from several investigators suggest in general that a number of induction techniques such as IM and IV ketamine, IV narcotics, and halothane with or without nitrous oxide can be used safely in the management of a child with cyanotic CHD. Unlike in adult patients, both nitrous oxide and ketamine have been shown to have no worsening effects on the pulmonary vasculature of young children with CHD.*

IV ketamine, $1-2 \mathrm{mg} / \mathrm{kg}$ with $100 \%$ oxygenation and paralyzed with vecuronium bromide, endotracheal tube of appropriate size sucured and ventilated with oxygen; anesthesia was maintained with IV infusion of propofol, fentanyl and intermittent bolus dose of vecuronium.

Dipamine 5-10 micrograms $/ \mathrm{kg} / \mathrm{min}$, milrinone $0.5-0.7$ microgram $/ \mathrm{kg} / \mathrm{min}$ and noradrenaline $0.05-0.1$ microgram $/ \mathrm{kg} /$ min was started after rewarming. With hemoglobin, electrolyte, blood sugar, blood gas, temperature, and blood pressure and rate rhythm of the heart is normal, Cardio pulmonary bypass was terminated

\section{Post-operative problems: \\ i. Low cardiac output-}

tricuspid valve regurgitation leads to right ventricular dilation which obstructs the filling of left ventricle and therefore reduces cardiac output. There maybe intracardiac shunt, which also decreases the cardiac output, leading to ineffective circulation and metabolic acidosis. Inotropic support with appropriate volume is the goal of therapy.

\section{ii. Pulmonary insufficiency-}

in Ebstein's anomaly, lung hyperplasia is almost always there, so it can complicate the pulmonary insufficiency. Care should always be taken to differenciate it from hyper inflation of the chest.

\section{iii. Residual tricuspid regurgitation-}

it is managed by appropriate inotropic support with after load reduction and meticulous volume replacement.

\section{iv. Postoperative dysrrhythmias-}

dysrrhythmias can occur in any type of cardiac operation. They have intrinsic abnormalities of conduction system they can produce any kind of arrhythmias. They can produce heart block if the tricuspid valve is replaced. Epicardial artial and ventricular pacing wire is very important.

\section{CONCLUSION}

Ebstein's anomaly is a rare complex congenital heart disease which consists of less than $1 \%$ of all congenital heart diseases. No two Ebstein are identical, each has its own presentation, morbidity, mortality, and natural history.

\section{REFERENCES}

1. Neonate with Congenital Heart Disease 2nd 1981, Sanders.

2. Anderson KR, et all Morphologic spectrum of Ebstein's anomaly of the heart, a review, Mayo clinic, 1979;54:174

3. Barber. G and Danelon G.K, Cardio respiratory response to exercise in Ebstein's anamoly, correlation of first heart sound to ill ultrasonic records of tricuspid valve movement. BY. Heart J, 1972;34:381

4. Benron L.M, Child J.S and et. Al: left ventricular geometry and function in adults with Ebstein's anomaly flow tricuspid valve, circulation 1987; 75:358

5. Nora I.S, Nora A.H, Lithium, Ebstein's anomaly and other heart defect. Laulet 1974, 2,594

6. Cappato R, Hebe S, Eeib C, ET all. Radio frequency current ablation of accessory pathway in Ebstein's anomaly, J. An. Coll cardiac, 1993;21

7. Saxena A, Frong L.V et al, left ventricular function in patients in 20 years of age with Ebstein's anomaly of tricuspid valve, Am.J.Candid, 1991; 67(2)217:219

8. Pediatric cardiac intensive care by Andlway C.

9. Cardiac Anesthesia for infants and children by Kambam

10. Wessel DL, Hickey PR, Pulmonary and systemic hemodynamic effect of bypass ventilation in infants after repair of congenital heart disease, Anesthesiology 67, A526, 1984

11. Kumar AE, Fyler DC, Ebstein's anomaly ; clinical profile and natural history- Aw.J cardio 1971;28;84:95 